\title{
The Effect of Carbon Fibers on the Tensile Behavior of Bitumen Beams
}

\author{
Monire Zokaei ${ }^{1} \&$ Saeid Hesami ${ }^{1}$ \\ ${ }^{1}$ Department Of Civil Engineering, Babol Noushirvani University Of Technology, Babol, Iran \\ Correspondence: Saeid Hesami, Department Of Civil Engineering, Babol Noushirvani University Of \\ Technology, Babol, Iran.
}

Received: August 2, 2021

Accepted: October 19, 2021

Online Published: October 27, 2021

doi:10.5539/mas.v15n6p33

URL: https://doi.org/10.5539/mas.v15n6p33

\begin{abstract}
Fatigue cracking is one of the most important types of failures, which decrease the asphalt pavement service life. Carbon fibers are amongst of the additives that have high tensile strength. It is expected this fiber reduce pavement cracks which increases the fatigue life of pavement. This paper experimentally investigated the effect of the carbon fibers on bitumen specimens. Hence, the effects of fiber characteristics such as length and fiber percentage on the indirect tensile strength and Marshall stability of asphalt mixture were studied. Then, the effect of fibers on bitumen and mastic behavior, which is the main objective of the study, was evaluated. Beam specimens were subjected to three-point bending tests to determine the effect of carbon fibers. Carbon fibers had a positive effect on the tensile strength of bitumen beams at loading rates of $0.5,2$, and $5 \mathrm{~mm} / \mathrm{min}$ up to $100 \%$. Mastic exhibited a similar behavior to pure bitumen in combination with fibers.
\end{abstract}

Keywords: carbon fiber, fatigue failure, bitumen beams, three-point bending

\section{Introduction}

\subsection{Introduce the Problem}

A very common structural pavement distress which leads to crack propagation in asphalt pavements is the fatigue effects. Fatigue refers to failure due to the repeated loading and dynamic load changes within the stress range less than the ultimate strength of the material. Fatigue occurs due to cyclic (or fluctuating) stress experienced by the structure under repetitive forces (Abtahi et al., 2010). These types of cracks first appear as small longitudinal cracks along the road axis and then propagated and take the shape of alligator's skin (Abtahi et al., 2010). The main cause of the occurrence of fatigue cracks is the low tensile strength of asphalt at moderate temperatures, which leads to the crack growth and some failures in the pavement structure (Aliha et al., 2018). Different types of additives are used to improve the properties of the bitumen and asphalt mixtures to enhance their tensile strength (Aliha et al., 2018). For example, fiber is one of the additives most commonly used to extend the fatigue life and improve the tensile properties of asphalt mixtures. Fiber additives are mainly used as the reinforcing materials in asphalt pavements to improve tensile properties and increase the strength to cracking (Arabani \& Shabani, 2019).

An accurate and comprehensive literature review showed that, usually fibers are used in asphalt for three main reasons: improving the mechanical properties of the mix (i.e. tensile strength, Marshall Strength, fatigue life and etc.), increasing electrical of the mixes, and to reusing different waste fibers (Badeli et al., 2018). The fiber type uses in asphalt is important in asphalt mixture reinforcement. Thus, it is necessary to provide fibers which not only have sufficient tensile strength and flexibility, but also have significant thermal resistance against high temperature at mixing time. Different types of fibers have been used in various researches. These researches include the use of fibers such as polypropylene, glass and basalt fibers, viscose, hemp, polyester, acrylic, carbon fibers, etc (Rizvi et al., 2015).

One of the important matters in asphalt containing fibers is the way of adding the fibers. Therefore, the mixing method can diverge depending on the properties of each fiber. In general, the fibers are mixed with the mixture in three ways. 1. Dry mixing, in which the fibers are first blended with aggregates and then with bitumen. 2. A mixing machine is used to completely mix the fibers with bitumen, and then the fibers are combined with aggregates. 3. The fibers are added step by step. Therefore, mixing has a significant effect on the uniform 
distribution and performance of the fibers in the mixture. Some studies compared the performance of several fibers regardless of the fact that the proper mixing of different fibers should be studied to fabricate the mixture (Klinsky et al., 2018). Hence, it is necessary to determine the best mixing method for each fiber (Liu \& Wu, 2011).

Carbon fiber is one of the types of fibers used in mixing and its effect on the improvement of the asphalt properties should be investigated. Carbon fiber is defined as a fiber which contains at least 90 percent carbon. Large varieties of fibers with specific characteristics are used to produce carbon fibers. The main specification of these fibers is their high tensile strength, which can affect the tensile properties and extend the fatigue life of asphalt mixtures. It is also expected that due to the carbon structure, when mixing with bitumen, which has a carbon structure, form a more uniform composite (Jahromi \& Khodaii, 2008). The characteristics and properties of carbon fiber reinforced asphalt mixtures were assessed in a research. It found that the addition of carbon fibers increases the mix's stability and voids in the mix while decreases flow value. They also found that the addition of fibers can improve the fatigue life and permanent deformation of the mixtures (Mirsayar, 2017). In addition, the very high melting temperature of these fibers is one of the parameters that allow the fibers to be mixed with bitumen at any temperature without changing the fibers' properties and shape (Omari et al., 2016).

Ghaffarpour Jahromi (2015) studied the effect of carbon nanofibers (CNFs) on the mechanical properties of asphalt. The researcher performed various experiments using Marshall Strength test, indirect tensile test, and creep test. The results indicated that addition of nanofibers could change the properties of the asphalt mixtures, increase its stability, and decrease the flow rate. Another study conducted at Louisiana University of America (2016) evaluated the functional response of asphalt mixtures containing carbon nanofibers. The main objective of the mentioned study was to fabricate an intelligent HMA mixture using the electrically conductive materials such as carbon nanofibers (CNFs). Then, HMA mixture modified with CNF was evaluated under different conditions of loading, frequency, and temperature (Saeed Ghaffarpour Jahromi, 2015).

Moreover, Wang et al. (2016) investigated the self-healing property of asphalt mixtures containing carbon fibers. Therefore, two types of carbon fibers with different percentages were used to modify the asphalt mixture. Results indicated an increase in the thermal conductivity of the specimens with asphalt mixtures modified with carbon fiber. Therefore, optimum percentage of the fibers was obtained with regard to the increased rate of the specimen internal temperature. Flexural test demonstrated the increased strength to fracture and crack growth. Consequently, the strength of the carbon fiber specimens after healing and application of microwave waves was higher than the specimens without fibers (Wang et al., 2016).

The asphalt layer in the pavement is usually composed of bitumen, aggregate, and approximately $5 \%$ of empty space (Harvey, J. A. F., 2000). According to the literature, cracking occurs in asphalt mixtures, either in the bitumen section of asphalt (cohesive failure), or at the surface of bitumen contact with the aggregate (adhesive failure), or as a result of the fracture of aggregates or a combination of all three (Di Benede, H. \& Olard, F., 2004). Several studies referred to different factors that may cause failure, including bitumen properties, relative thickness of mastic around the fine and coarse aggregates, type of aggregate, temperature, pore pressure, and interfacial stress (Moghadas Nejad et al., 2014). Therefore, investigation of the bitumen behavior would significantly help examine the fatigue and fracture properties of asphalt.

Pertillo and Cebon (2013) conducted a numerical and experimental evaluation of the mechanism of bitumen beams cracking. The researchers performed their experiments on bitumen rather than on the mixture to run the microstructural studies on the pure bitumen fracture (Kim, Y. K., 2011). The fracture parameters used in this study were $\mathrm{K}_{\mathrm{IC}}, \mathrm{G}_{\mathrm{IC}}$, and $\mathrm{J}$ integral, which were used to evaluate fracture properties by three-point bending experiment on pure bitumen beams. This study examined the effect of temperature changes and permeation on bitumen characteristics, which provided valuable results for a wide range of temperatures and loading rates (Portillo \& Cebon, 2013).

\section{Research Objective and Methodology}

In general, carbon fibers can be used in asphalt mixture for various purposes. Directly after adding fibers to asphalt mixture, its strength increases and "bridging" phenomenon occurs between the components of asphalt mixture. Fig. 1 illustrates the separation of a material with fiber into two parts with directional distribution at fracture. The part of fibers which goes through both sides of the crack surface will grow a bridge shape which can postpone more asphalt cracking (Figure 1). Due to the tendency of the mixture to open cracks under external stresses, part of the stress transmits to the fibers in form of tensile stress. Enduring tensions by bridge fibers can sew the cracks and reduce the crack tips and stress -intensity coefficients which stops or reduces crack 
propagation rates (Dubois et al., 2016). This paper examined the effect of these fibers on the improvement of the tensile strength. This event increases the mixtures resistance against fatigue cracking.
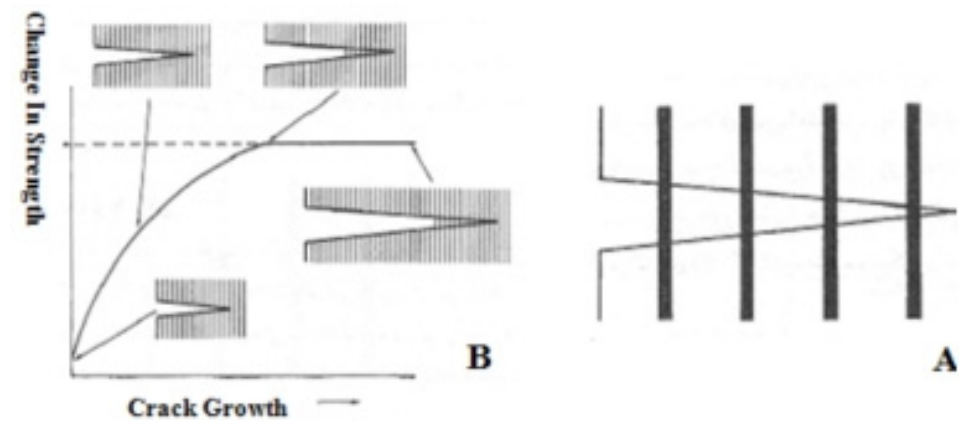

Figure 1. Bridging phenomena at the cracked plates (a) The effect of aligned fibers at the cracked plate (b) The effect of fibers on strength increase of fibered aggregate (Dubois et al., 2016)

The reaction between the fibers and the base material at the cracked plate will cause the crack to be deviated from its original plane and make a non-planar crack (Fig. 2). Typically, a crack begins to open at its mouth and grows. But after the opening it will deviates from the plane and its growth in each of the crack deviation decreases and stops. The fiber types which uses in asphalt are important in the fiber-reinforced asphalt mixture. Thus, it is necessary to provide fibers which not only have sufficient tensile strength and flexibility, but also have significant thermal resistance against high temperature at mixing time. Rutting which is largely due to lack of shear strength of pavement surface is the permanent deformation due to roughness in road longitudinal profile and other undesirable effects that causes pavement deterioration propagation.
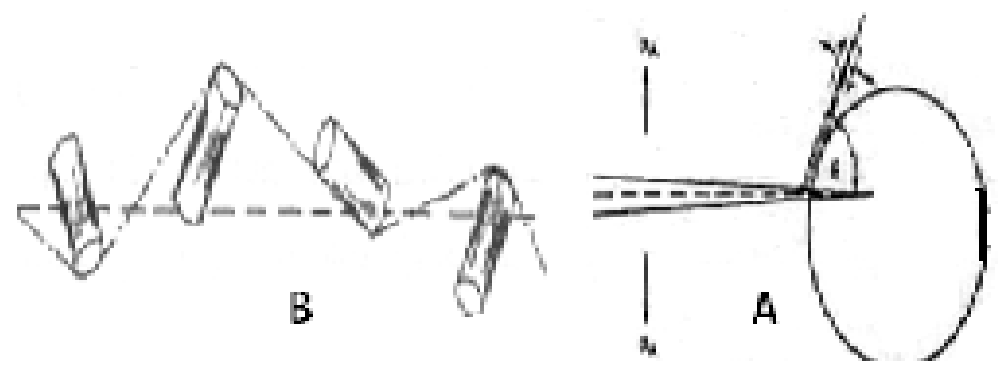

Figure 2. Deviations on crack propagation (a) the crack tip meets the fiber (b) The effect of non-aligned fibers in crack deviation (Bueno et al., 2015)

In order to control rutting resistance directly, rutting apparatus such as Hamburg Wheel Tracking Test and other similar standard methods is being used by researchers (Campbell et al., 2018); however, this method was not used in this research due to limitations of laboratory equipment. Others recommend parameters such as the Marshall Ratio based on limited access to rutting testing equipment, used by some other research institutions such as the UK Transport Research Laboratory. This study used the latter case. Marshall Ratio (MR) is the ratio of stability to flow value of the mixture which used to determine the potential of rutting.

The percentage of fibers were generally obtained in terms of the total weight of the mixture, but in fibers such as carbon, which have low denier, it would better to obtain the optimum percentage of fibers at a finer and more accurate scale. Hence, this paper calculated the percentage of fibers in terms of the weight percentage (\%) of bitumen. Fiber length is also very important; therefore, the optimum length should be determined according to the research objective. In addition, the paper aimed to increase the tensile strength of the asphalt, thus requiring a length to be effective in improving tensile strength and proper mixing. In other words, it was neither long enough to cause the fibers to be tangle together nor short enough to provide the necessary holding to improve tension and prevent the crack growth. However, so far, no research has provided an accurate evaluation of the optimum percentages and length of fibers.

Carbon fibers have been studied to improve tensile, fracture, and self-healing properties; therefore, different percentages of fibers have been used, which varied depending on the type of experiments in each study. Moreover, the used mixing design method would be also very important. Previous research indicated that nature and properties of bitumen have a significant effect on the fatigue life of the asphalt mixtures (Badeli et al., 2018). 
Therefore, the study of the bitumen behavior has a significant effect on the fatigue and fracture of the asphalt mixtures.

Many additives used in the pavement modification are directly tested on bitumen; however, in the case of the carbon fibers, a combination of fibers and bitumen would not be able to do tests such as BBR and DSR and do not place in the molds (Arabani \& Shabani, 2019). For this reason, research would not deal with the carbon fiber testing on bitumen and mastic. Crack spread usually occurs in the bitumen portion of the asphalt and improving the bitumen fracture properties can be a more appropriate solution to increase the fracture strength of the mixture. Since bitumen is combined with filler and makes significant changes in its behavior, it is more appropriate to investigate the mastic behavior. Figure 1 depicts the position of the bitumen beam in the three-point bending machine (Portillo \& Cebon, 2013).

This loading method can also be seen in a study conducted by Aliha et al. In this paper low temperature crack growth behavior of bitumen (with penetration grade of 30/40) is investigated experimentally using a new and novel test configuration called inclined notched bend beam (INBB) specimen (Aliha et al., 2018).

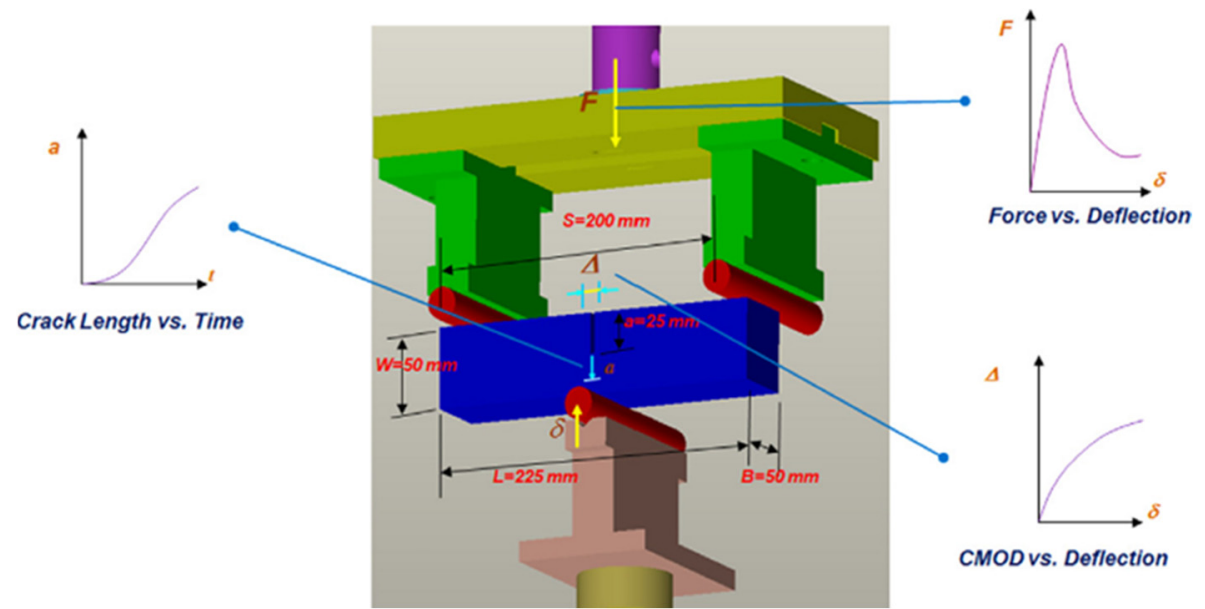

Figure 3. A schema of the testing device and obtained diagrams (Portillo \& Cebon, 2013)

\section{Specifications of the Materials}

Materials used in this study included bitumen, aggregates, and carbon fibers. The bitumen used in the study was provided from Isfahan Jey Oil Company with 60-70 penetration grades. Table 1 presents the properties 'of study 60-70 penetration grade bitumen. The stone materials used in the study were the crushed stone and the stone powder passed through \#200 sieves was also used as filler. The results of the grading test were shown as the grading curve. It is notable that continuous grading with a maximum size of $19 \mathrm{~mm}$ was used in the study. The grading testing was performed according to ASTM-D3515. Table 2 reports the grading used with upper and lower limits. Figure 4 shows the carbon fiber used in this project.

Table 1. Specifications of the used bitumen

\begin{tabular}{lllll}
\hline \multicolumn{2}{l}{ Allowable limits } & \multirow{2}{*}{ Test results } & Standard of the testing method & Experiment \\
\cline { 1 - 2 } Lower limit & Upper limit & & & \\
\hline 1.01 & 1.06 & 1.013 & ASTM D3289 & Specific weight $(\mathrm{gr} / \mathrm{cm} 3)$ \\
60 & 70 & 68 & ASTM D5 & Penetration rate $(0.1 / \mathrm{mm})$ \\
49 & 56 & 49.4 & ASTM D36 & Softness point $\left({ }^{\circ} \mathrm{C}\right)$ \\
100 & - & +100 & ASTM D113 & Elasticity $(\mathrm{cm})$ \\
232 & - & 334 & ASTM D92 & Flash point $\left({ }^{\circ} \mathrm{C}\right)$ \\
99 & - & 99.97 & ASTM D2042 & Solubility (wt\%) \\
- & 0.2 & 0.003 & ASTM D6 & Weight loss due to temperature $(\mathrm{wt} \%)$ \\
- & 20 & 7.8 & ASTM D6 \& D5 & Decrease in the penetration rate after \\
& & & & $\begin{array}{l}\text { loss due to temperature }(\%) \\
\text { bitumen spot test }\end{array}$ \\
\hline
\end{tabular}


Table 2. Grading the stone materials

\begin{tabular}{llll}
\hline Size of sieve & $\begin{array}{l}\text { Percentage of the } \\
\text { selective passed (\%) }\end{array}$ & $\begin{array}{l}\text { The passed upper } \\
\text { limit }(\%)\end{array}$ & $\begin{array}{l}\text { The passed lower } \\
\text { limit }(\%)\end{array}$ \\
\hline 12.5 & 100 & 100 & \\
9.5 & 90 & 100 & 90 \\
4.75 & 60 & 85 & 55 \\
2.36 & 35 & 67 & 32 \\
0.3 & 10 & 23 & 7 \\
0.075 & 2 & 10 & 2 \\
\hline
\end{tabular}

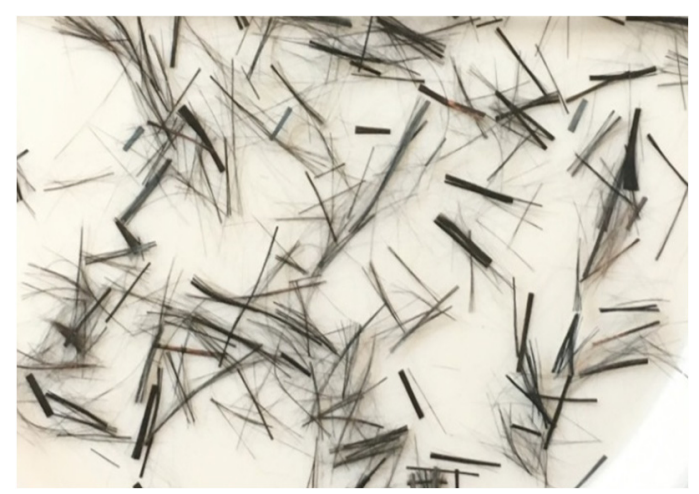

Figure 4. Carbon fibers

\section{Mixing Design Method and Experiments}

\subsection{Determination of Optimum Fiber Content}

Selecting the appropriate amount of fiber content in asphalt mixtures is important. Too low fiber content may increase the probability of creating a weak cross section for cracks propagation in the surface. Also, use of too high fiber content may reduce the cohesion between aggregates and shrink all fibers in one place.

Optimum bitumen was determined by the Marshall mixing method according to ASTM-D1559 standard. Based on this method, 18 cylindrical specimens with $3.5,4,4.5,5,5.5$, and $6 \mathrm{wt} \%$ bitumen (three specimens per percentage) were first fabricated according to the standard and then tested. This study determined the optimum bitumen content according to the five Marshall Stability quantities, specific weight, asphalt void, void filled with bitumen, and the stone materials void. Finally, the optimum bitumen content was $4.5 \mathrm{wt} \%$.

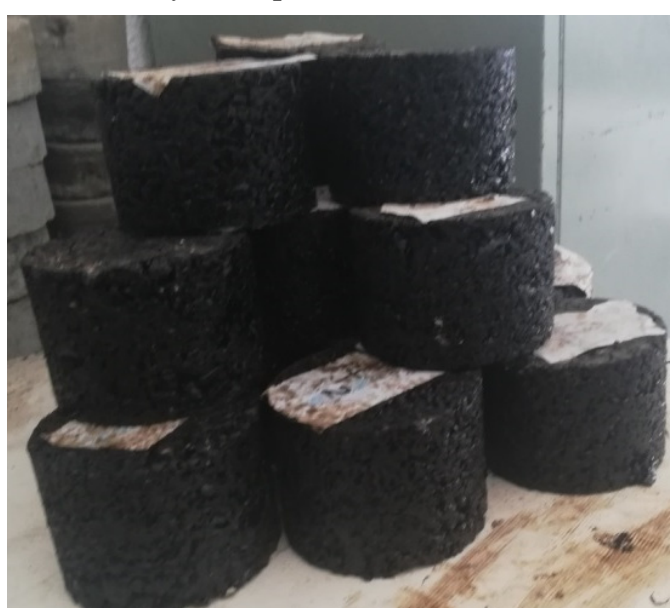

Figure 5. Marshall Samples made

Cylindrical specimens were prepared using the Marshall method (Figure 5). In order to achieve a uniform distribution of the fibers and a homogeneous composite, the stone materials were initially heated to $177-191^{\circ} \mathrm{C}$ and bitumen to $144-148^{\circ} \mathrm{C}$ (ASTM E 399, 2005). In the first method, the stone materials and bitumen were 
mixed in a rotary mixer. Then, the separated fibers were added to the mixture and the mixing process continued. After examining the specimens, the fiber pellets were observed inside the specimen. In the second method, the used fibers, filler, and bitumen were mixed for $100 \mathrm{~s}$. Afterwards the sand was added to the mixture and stirred for another $200 \mathrm{~s}$ to achieve a homogeneous mixture. In this method, the fiber pellets attached to the rotary shaft after the mixing action and removed from the specimen; however, the mixture had a more uniform distribution than the first method. In the third method, the stone materials and bitumen were mixed in the mixer. Then, the mixed fibers were added step by step. Finally, the best mixing and distribution conditions were observed in this method.

The content of the fibers used in the asphalt specimens was $0.5,1,1.5,2,2.5$, and $3.5 \mathrm{wt} \%$ bitumen. Therefore, Marshall Test and Indirect Tensile Test (IDT) were run to determine the optimum content for each fiber percentage and finally the optimum fiber percentage was determined. According to ASTM-D6931 standard, tensile strength of the cylindrical specimens was determined by IDT (ASTM D6931, 2012). This test was used to determine the indirect tensile strength of the asphalt specimens. The test was run at $25^{\circ} \mathrm{C}$ and a loading rate of 50 $\mathrm{mm} / \mathrm{min}$.

Indirect tensile strength (ITS) tests were carried out according to AASHTO-T283. Cylindrical specimens were loaded diametrically across section. The loading caused a tensile deformation perpendicular to the loading direction, which yielded a tensile failure. The maximum tensile strength can be expressed by the equation (1).

$$
\mathrm{S}=\left(\frac{2 \mathrm{P}_{\max }}{\pi t d}\right)
$$

Where:

$\mathrm{Sr}=$ Tensile strength of specimen $(\mathrm{N} / \mathrm{mm} 2)$

Pmax $=$ The maximum vertical force exerted $(\mathrm{N})$

$\mathrm{t}=$ Thickness of specimen $(\mathrm{mm})$

$\mathrm{d}=$ Diameter of specimen $(\mathrm{mm})$

Values of Marshall Ratio (MR) for different percentages of fiber versus different bitumen contents are illustrated in Figure 6. Generally, mixes containing carbon fiber had more MR in comparison with samples without fiber. More rutting resistance could be predicted for these samples.

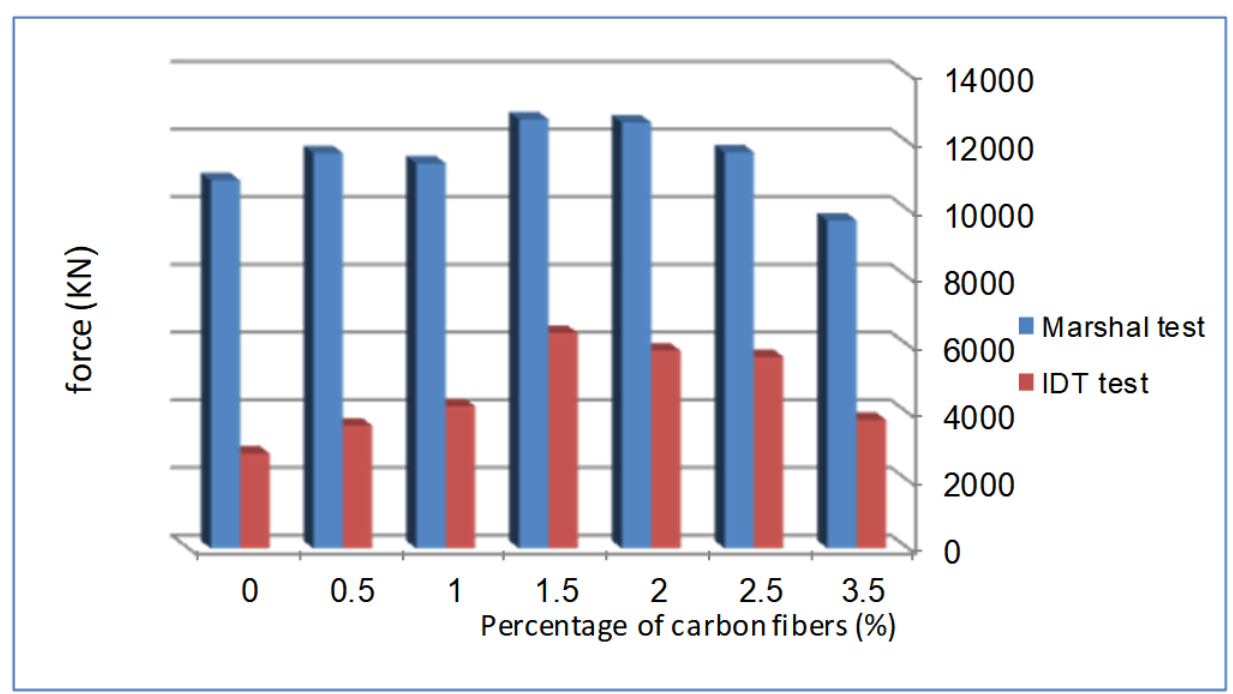

Figure 6. Results of Marshall Test and IDT for different contents (\%) of carbon fibers

\subsection{Determination of Optimum Fiber Length}

Fibers length is one of the most important parameters in the effectiveness of fibers. High fiber lengths cause the fibers to be gathering during mixing and insufficient adhesion of bitumen and aggregates. In order to determine the optimum fiber length, the asphalt specimens containing carbon fibers were fabricated using the Marshall mixing design (ASTM D1559) and applying 75 strokes to each side of the specimen. Different lengths of fibers used in the asphalt specimens were 10,15,20,25, and $30 \mathrm{~mm}$. All specimens were fabricated with optimum fiber content, which was equal to $1.5 \mathrm{wt} \%$ bitumen. To determine the optimum fiber length, Marshall Test and 
Indirect Tensile Test (IDT) were run on each fiber length and finally the optimum fiber length was determined. (Figure 7)

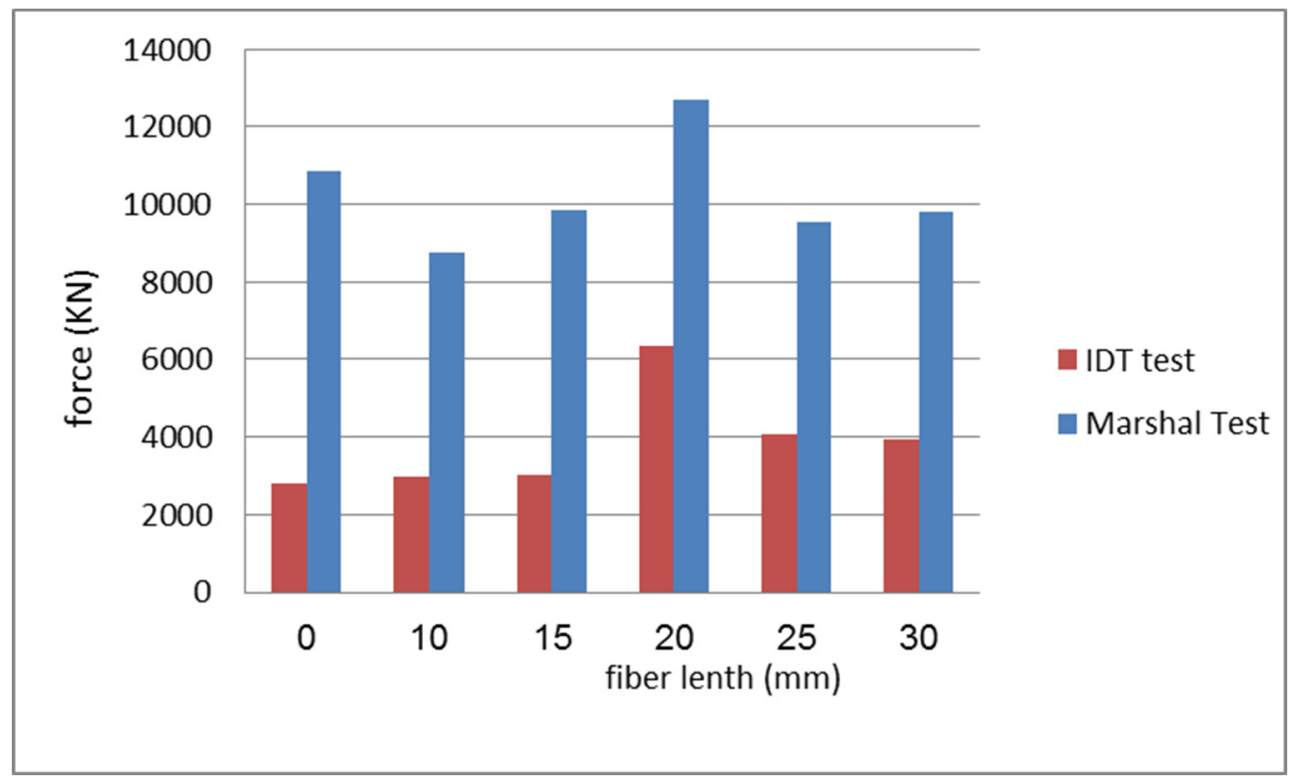

Figure 7. Results of Marshall and indirect tensile tests for different lengths of the carbon fibers

\subsection{Three-Point Bending Test of Bitumen and Mastic Beams}

\subsubsection{Fabrication of the Bitumen Specimens}

In order to test the bitumen specimens, it was necessary to provide molds with suitable dimensions for making the specimen. The mold size was $25 \times 25 \times 150 \mathrm{~mm}$. Since the optimum length of the fibers in the mixture was $20 \mathrm{~mm}$, the specimen size was considered more than the optimum length. Figure 8 depicts the molds made for testing.

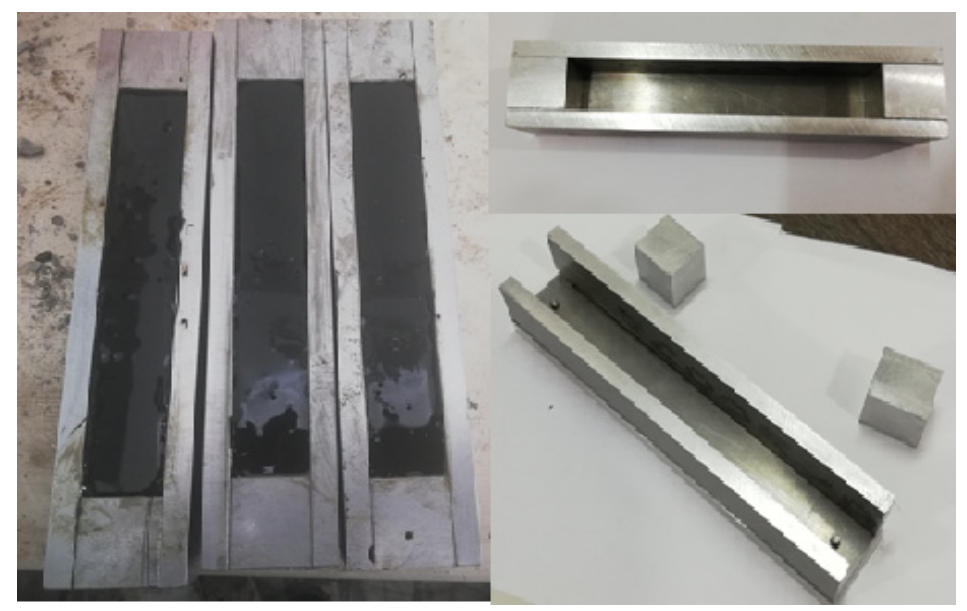

Figure 8. Molds made for preparing the bitumen specimens

In order to prevent the bitumen and materials from binding to the mold and easily remove the specimens from the mold, a paste of talc and glycerin oil was prepared and all the inner surfaces of the mold were impregnated before pouring the bitumen into the mold (Figure 9). Therefore, the specimen was easily removed from the mold. 


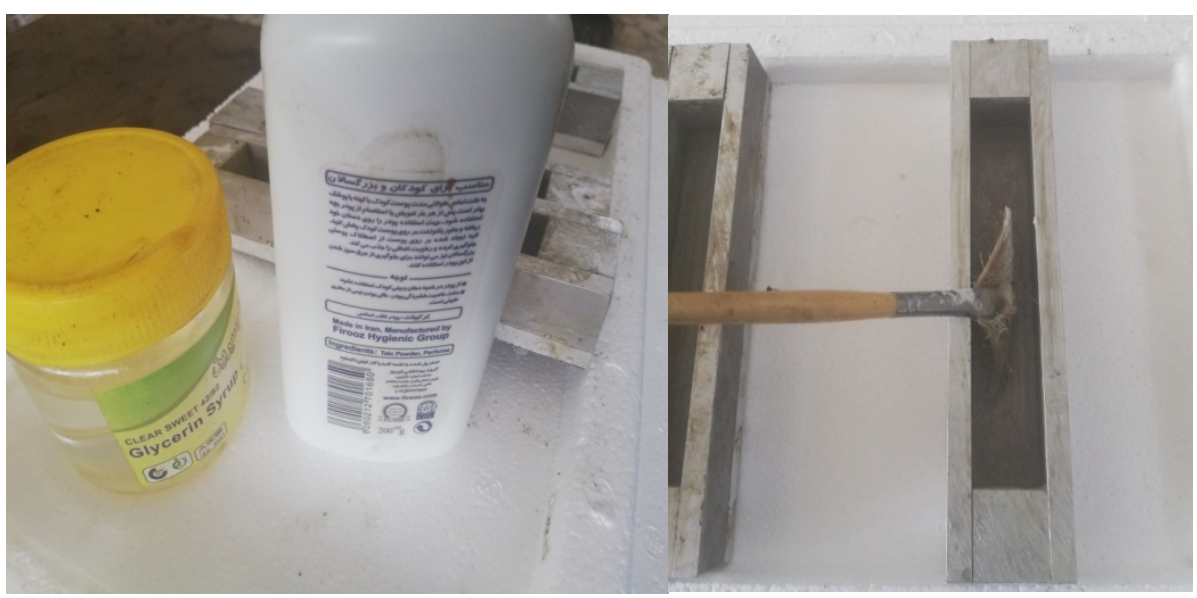

Figure 9. Preparation of the specimen mold with talc and glycerin oil

In order to determine the effect of the fibers on bitumen and mastic, the specimens were fabricated in four states and then the results of the experiments were compared.

1) Pure bitumen specimen (A): These specimens were fabricated as a control specimen for comparison with other modes.

2) Bitumen and filler specimen (B): Combining bitumen with filler changed the mechanical properties of bitumen and was necessary for proper examination of the tensile properties of the mixture, mastic, and the effect of the fibers on it.

3) Bitumen specimen with carbon fibers (C): This specimen was fabricated by combining bitumen and fibers with the optimum percentage.

4) A specimen containing bitumen, filler, and carbon fiber (D): These specimens were fabricated based on the mixing design and optimum fiber percentage.

The content of fiber, filler, and bitumen used in the specimen fabrication was obtained from the mixing design experiments and determining the optimum percentage. Moreover, all specimens were fabricated with $20 \mathrm{~mm}$ fibers as the optimum fiber length. Table 4 summarizes the above procedures.

Table 3. Specimen Specifications

\begin{tabular}{llll}
\hline Sample A & Sample B & Sample C & Sample D \\
\hline Pure bitumen & Bitumen and filler & Bitumen and carbon fibers & Bitumen, filler, and carbon fibers
\end{tabular}

\subsubsection{Testing the Bitumen Beams}

Bending test is a test of the mechanical properties of the materials, in which the specimen strength against bending is evaluated. This test is usually performed by a universal tension machine in either three-point or four-point bending. According to the bending test, force was applied from the top by the piston to the tested specimen and the piston moved to the tested specimen at a specified speed, usually between 0.1 and $30 \mathrm{~mm} / \mathrm{min}$. When it collided with the specimen, the applied force increased, and the specimen moved downward at the contact surface. The bending tester software draws the amount of the applied force and the amount of bending of the specimen in a two-dimensional diagram where the vertical axis represents the force and horizontal axis represents the amount of deformations. During the bending test, compressive and tensile stresses were formed at the upper and lower surfaces of the specimen. However, since tensile stress of the materials was usually lower than their compressive stress, if the specimen was brittle, it would fail or crack from the lower part.

Three-point bending test was run on pure bitumen and mastic as well as the fiber composite. Three loading rates of $0.5,2$, and $5 \mathrm{~mm} / \mathrm{min}$ were considered for experiments, and all four bitumen beam models were tested at each loading rate to evaluate the effect of the loading rate. Upon the preparation of the specimens and placement of the specimens on the device (Figure 10), the desired settings were made on the device and then testing began. The settings included entering the specimen dimensions, support distance, type of test, and so forth. The device draws the force-deformation curve for the specimen being tested. 


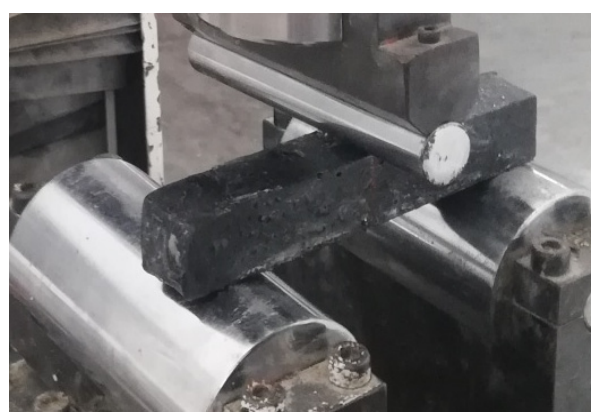

Figure 10. Setting bitumen beam in the test machin

\subsubsection{Results of the Three-Point Bending Test}

Three-point bending test was performed on pure bitumen and mastic as well as the fiber composite. Three loading rates of $0.5,2$, and $5 \mathrm{~mm} / \mathrm{min}$ were considered for the tests, and all four bitumen beam models were tested at each loading rate to evaluate the effect of the loading rate.

Upon the preparation of the specimens and placement of the specimens on the device, the desired settings were made on the device and then testing began. The settings included entering the specimen dimensions, support distance, type of test, and so forth. Figures 11, 12, and 13 depict each of the four specimens at each loading rate.

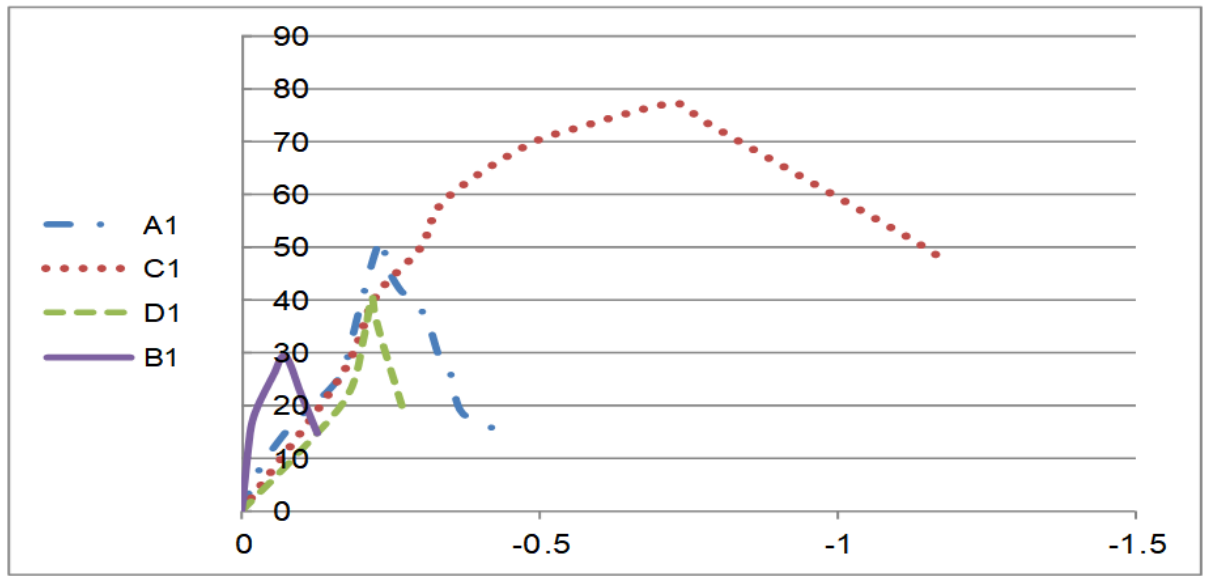

Figure 11. Force-displacement diagram of the four specimens at a loading rate of $0.5 \mathrm{~mm} / \mathrm{min}$

According to Figure 11, carbon fibers significantly improved the tensile properties of bitumen and mastic. This improvement was thoroughly obvious by comparing $\mathrm{A}$ and $\mathrm{C}$ diagrams for bitumen as well as cmparing $\mathrm{B}$ and $\mathrm{D}$ diagrams for mastic. Moreover, the difference of bitumen behavior after mixing with bitumen indicated the necessity of investigating mastic.

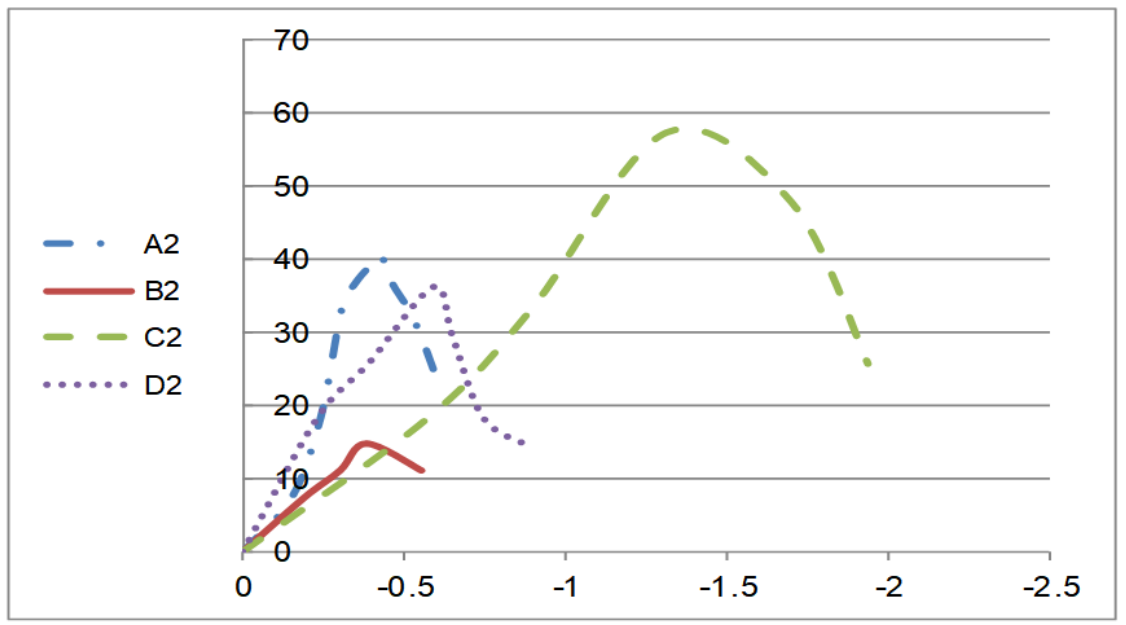

Figure 12. Force-displacement diagram of the four specimens at a loading rate of $2 \mathrm{~mm} / \mathrm{min}$ 


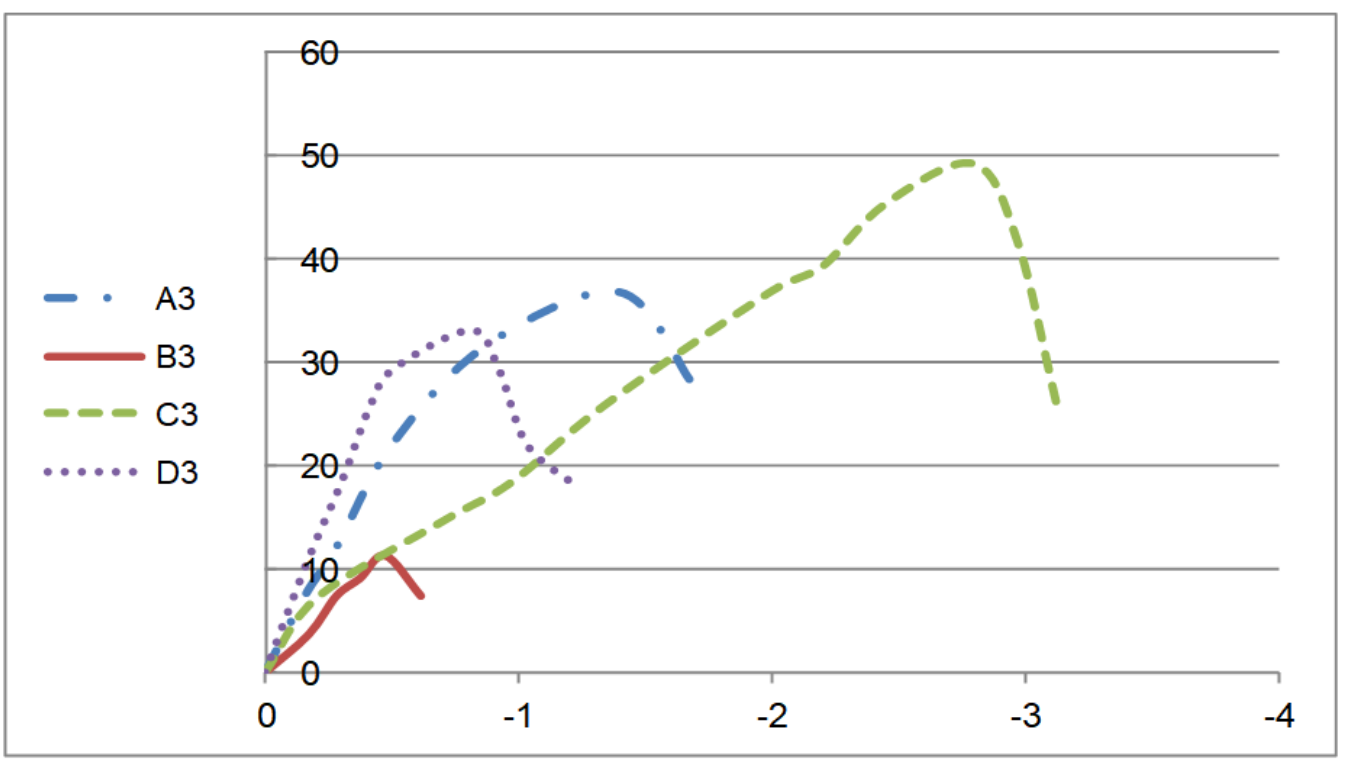

Figure 13. Force-displacement diagram of the four specimens at a loading rate of $3 \mathrm{~mm} / \mathrm{min}$

For better comparison and conclusion, diagrams were plotted in Figures 14 and 15 to compare the maximum load tolerated at each loading rate for all four types of the bitumen beam as well as deformation at this loading rate. As it is clear, in both diagrams, the increase in the amount of tolerable load in the samples containing carbon fibers shows the positive effect of these fibers on bitumen and mastic.

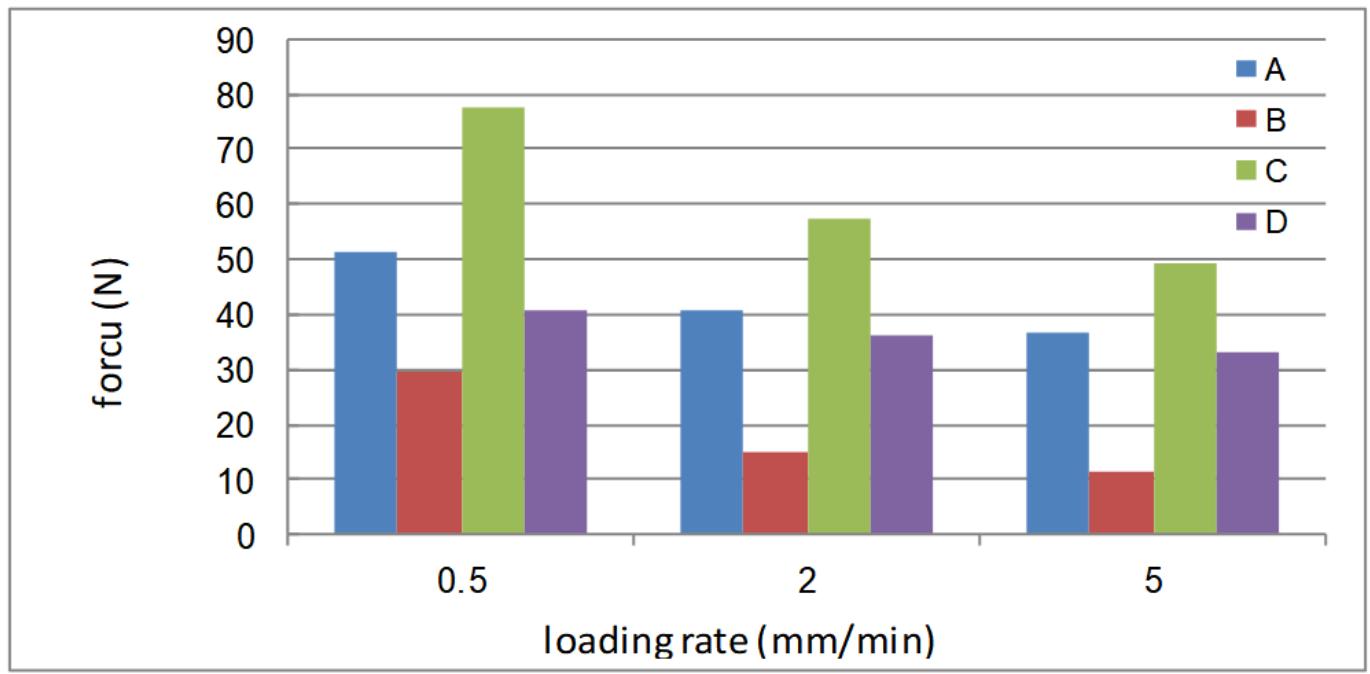

Figure 14. Comparison of the maximum force applied at each loading rate in $\mathrm{mm} / \mathrm{min}$ for different types of bitumen beams

Figure 14 presents the maximum load per beam at each loading rate. As seen, A represents specimens containing the pure bitumen, B shows specimens containing bitumen and filler beams, C represents bitumen beams containing carbon fibers, and D displays bitumen beams containing filler and carbon fiber.

- Bitumen beams exhibited higher strength at all three loading rates of $0.5,2$, and $5 \mathrm{~mm} / \mathrm{min}$ with the addition of carbon fibers. In both cases, they tolerated loads about three and two times more.

- Mastic also showed a similar behavior to bitumen in combination with fibers. At a loading rate of $0.5,2$, and $5 \mathrm{~mm} / \mathrm{min}$, carbon fibers exhibited higher strength upon the addition of the carbon fibers. 


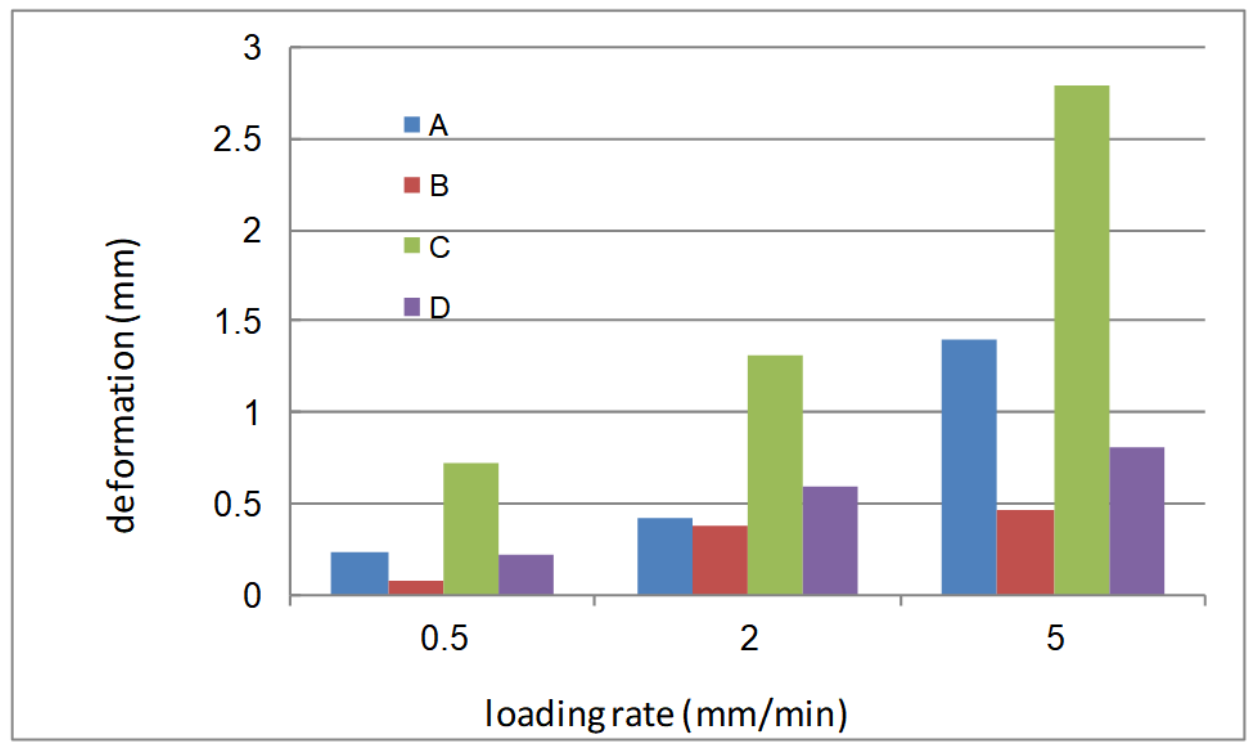

Figure 15. Comparison of deformation at maximum loading rate $(\mathrm{mm} / \mathrm{min})$ for different types of bitumen beams

The above diagram (Figure 15) depicts the rate of deformation to reach the maximum load and yield the specimen for each beam and at each loading rate. The figure can represent the effect of fibers on the elasticity of bitumen and mastic specimens.

- Bitumen beams exhibited a higher deformation at $0.5,2$, and $5 \mathrm{~mm} / \mathrm{min}$ loading rates with the addition of carbon fibers. Therefore, a significant increase could be observed at all three loading rates, indicating an increase in the tensile strength.

- Regarding the increased deformation, mastic also showed a behavior similar to that of pure bitumen in combination with fibers. As the carbon fibers increased, the rate of deformation to reach the yield state increased about twice at the loading rates of $0.5,2$, and $5 \mathrm{~mm} / \mathrm{min}$. Therefore, it could tolerate tension twice more than before, which was a major weakness of the asphalt and our objective was to improve this property.

\section{Conclusion}

An important parameter in the effectiveness of fibers to improve the asphalt properties is how to mix and uniformly distribute the fibers in the mixture. The present study investigated three different methods and determined the best mixing method. Moreover, specimens were fabricated with the above method and used in experiments. The best method was to mix the fibers after mixing bitumen and aggregate step by step, in order to obtain the least amount of the gathered fibers.

- After asphalt samples contained fibers compaction process, the most effective fibers were those placed in the stated direction and parallel to the surface; while, the angled fibers were less effective. However, the placement of fibers cannot be controlled in samples preparation. The amounts of fibers should not be so low which create a weak cross section for the production of cracks in the surface. Also their amounts should not be so high which leads to reduce the cohesion between aggregates and to avoid fibers to be gathered in one place. There was a certain optimum percentage for each type of fiber so that adding more did not make a significant change in the improvement of the desired properties. This optimum percentage for carbon fibers was 1.5 times the weight percentage of bitumen according to the diagram shown in Figure 3.

- Fiber length is one of the most important parameters in the effectiveness of fibers in modifying the asphalt mixture and uniform distribution of these fibers. It was found that very short fibers did not have a positive effect on the tension and crack growth, and long fibers caused agglomerating and incorrect mixing. Since carbon fibers tolerate high tensile forces, an optimum length should be obtained to utilize this property in order to increase the mixture elasticity, decline the mixture strength, provide a uniform distribution, and prevent the crack growth. It is notable that a $20 \mathrm{~mm}$ fiber was obtained as the optimum length in this study (Figure 4). In addition, the analysis of the results demonstrated the presence of carbon fibers can improve the cohesion of asphalt mixtures and when cracking appears on asphalt mixtures, these fibers can act as a connector to the bridging performance, and then can prevent the crack propagation. 
- Carbon fiber had a positive effect on the strength tolerated by bitumen beams at loading rates of $0.5,2$, and $5 \mathrm{~mm} / \mathrm{min}$ and increased the rate of the tolerated load up to the specimen yield point by two times. In this case, mastic exhibited a similar behavior to pure bitumen in combination with fibers. At the loading rates of $0.5,2$, and $5 \mathrm{~mm} / \mathrm{min}$, as the carbon fibers added, the loading rate increased. Nonetheless, to better understand the behavior of the mastic, it is suggested to design mixture with the carbon fibers to properly determine the filler and bitumen ratio.

- Bitumen beams exhibited higher deformation at $0.5,2$, and $5 \mathrm{~mm} / \mathrm{min}$ loading rates after the addition of the carbon fibers. Regarding the increased deformation of mastic, a behavior similar to that of pure bitumen was observed in combination with fibers. In all three rates, the rate of deformation increased to more than two times to reach the yield state. Therefore, the specimens tolerated further tension before rupture and crack initiation, which meant an increase in the tensile properties and fatigue life. Thus, carbon fiber would play an important role in increasing the pavement life.

\section{References}

Abtahi, S. M., Shaikhzade, M., \& Hejazi, S. M. (2010). Fiberreinforced asphalt-concrete- A review. Construction and building material, 24, 871-877. https://doi.org/10.1016/j.conbuildmat.2009.11.009

Aliha, M. R. M., Shaker, S., \& Keymanesh, M. R. (2018). Engineering Fracture Mechanics.

ASTM D1559. (1998). Test method for resistance of plastic flow of bituminous mixtures using Marshall Apparatus. Annual Book of ASTM Standards USA.

ASTM D6931 - 1. (2012). Standard Test Method for Indirect Tensile (IDT) Strength of Bituminous Mixtures. American Society for Testing and Materials.

ASTM Standard E 399. (2005). Standard test method for plane-strain fracture toughness of metallic materials.

ASTM-D3515. Standard specification for hot-mixed, hot-laid bituminous.

Bueno, M., Hugener, M., \& Partl, M. N. (2015). Fracture toughness evaluation of bituminous binders at low temperatures. Materials and Structures, 48(9), 3049-3058. https://doi.org/10.1617/s11527-014-0378-4

Di Benede, H., \& Olard, F. (2004). Fracture toughness and fracture energy of bituminous binders at low temperatures. In 5th international RILEM conference, Limoges, France.

Dubois, F., Moutou-Pitti, R., Picoux, B., \& Petit, C. (2012). Finite element model for crack growth process in concrete bituminous. Adv Engng Sof, 44(1), 35-43. https://doi.org/10.1016/j.advengsoft.2011.05.039

Hashim R. Rizvi, Mohammad Jamal Khattak, Mohammad Madani, \& Ahmed Khattab, (2016). Piezoresistive response of conductive Hot Mix Asphalt mixtures modified with carbon nanofibers. Construction and Building Materials, 106, 618-631. https://doi.org/10.1016/j.conbuildmat.2015.12.187

Jahromi, S. G., \& Khodaii, A. (2008). Carbon fiber reinforced asphalt concrete. The Arabian Journal for Science and Engineering, 33, 355-364.

Kim, Y. K. (2011). Cohesive zone model to predict fracture in bituminous materials and asphaltic pavements: state-of-the-art review. International Journal of Pavement Engineering, 12(4), 343-356. https://doi.org/10.1080/10298436.2011.575138

Klinsky, L. M. G., Kaloush, K. E., Faria, V. C., \& Bardini, V. S. S. (2018). Performance characteristics of fiber modified hot mix asphalt. Construction and Building Materials, 176, 747-752. https://doi.org/10.1016/j.conbuildmat.2018.04.221

Mahyar Arabani, \& Amir Shabani. (2019). Evaluation of the ceramic fiber modified asphalt binder. Construction and Building Materials, 205, 377-386. Iran. https://doi.org/10.1016/j.conbuildmat.2019.02.037

Mirhosseini, S. F., Khabiri, M. M., Kavussi, A., \& Kamali, M. J. (2016). Applying surface free energy method for evaluation of moisture damage in asphalt mixtures containing date seed ash. Construction and Building Materials, 125, 408-416. https://doi.org/10.1016/j.conbuildmat.2016.08.056

Mirsayar, M. M. (2017). On the low temperature mixed mode fracture analysis of asphalt binder-Theories and $\begin{array}{lllll}\text { experiments. } \quad \text { Engineering } & \text { Fracture }\end{array}$ https://doi.org/10.1016/j.engfracmech.2017.10.010

Moghadas Nejad, Fereidoon, Morteza Vadood, \& Seeyamak Baeetabar. (2014). Investigating the mechanical properties of carbon fibre-reinforced asphalt concrete. Road Materials and Pavement Design, 15(2), 465-475. https://doi.org/10.1080/14680629.2013.876442 
Omari, I., Aggarwal, V., \& Hesp, S. (2016). Investigation of Two Warm Mix Asphalt Additives. International Journal of Pavement Research and Technology, 9(2), 83-88. https://doi.org/10.1016/j.ijprt.2016.02.001

Ossa, E. A., Deshpande, V. S., \& Cebon, D. (2005). Phenomenological model for monotonic and cyclic behavior $\begin{array}{llllll}\text { of pure bitumen. } J \text { Mater Civ Engng, 17(2), } & \text { 188-197. }\end{array}$ https://doi.org/10.1061/(ASCE)0899-1561(2005)17:2(188)

Ossa, E. A., Deshpande, V. S., \& Cebon, D. (2010). Triaxial deformation behaviour of bituminous mixes. $J$ Mater Civ Engng, 22(2), 124-135. https://doi.org/10.1061/(ASCE)0899-1561(2010)22:2(124)

Portillo, O., \& Cebon, D. (2012). Modeling failure of bitumen films in tension. Journal of Engineering Mechanics, 138(11). https://doi.org/10.1061/(ASCE)EM.1943-7889.0000417

Portillo, O., \& Cebon, D. (2013). Experimental and numerical investigation of fracture mechanics of bitumen beams. Engineering Fracture Mechanics, (97), 281-296. https://doi.org/10.1016/j.engfracmech.2012.10.010

Prabir Kumar Das, Denis Jelagin, \& Björn Birgisson. (2013). Evaluation of the low temperature cracking performance of asphalt mixtures utilizing HMA fracture mechanics. Construction and Building Materials, 47, 594-600. https://doi.org/10.1016/j.conbuildmat.2013.05.031

Saeed Badeli, Alan Carter, Guy Doré, \& Saeed Saliani. (2018). Evaluation of the durability and the performance of an asphalt mix involving Aramid Pulp Fiber (APF): Complex modulus before and after freeze-thaw cycles, fatigue, and TSRST tests. Construction and Building Materials, 174, 60-71. Canada. https://doi.org/10.1016/j.conbuildmat.2018.04.103

Saeed Ghaffarpour Jahromi. (2015). Effect of Carbon Nanofiber on Mechanical Behavior of Asphalt Concrete, International Journal of Sustainable Construction Engineering \& Technology, 6(2), 57-66. Retrieved from https://publisher.uthm.edu.my/ojs/index.php/IJSCET/article/view/1183

Sophie Campbell, Haibo Ding, \& Simon, A. M. (2018). Hesp, Double-edge-notched tension testing of asphalt $\begin{array}{lllll}\text { mastics. Construction and } & \text { Building }\end{array}$ https://doi.org/10.1016/j.conbuildmat.2018.01.094

Xiaoming Liu, \& Shaopeng Wu. (2011). Study on the graphite and carbon fiber modified asphalt concrete. Construction and Building Materials, 25(4), 1807-1811. https://doi.org/10.1016/j.conbuildmat.2010.11.082

Zigeng Wang, Qingli Dai, David Porter, \& Zhanping You. (2016). Investigation of microwave healing performance of electrically conductive carbon fiber modified asphalt mixture beams. Construction and Building Materials, 126, 1012-1019. https://doi.org/10.1016/j.conbuildmat.2016.09.039

\section{Copyrights}

Copyright for this article is retained by the author(s), with first publication rights granted to the journal.

This is an open-access article distributed under the terms and conditions of the Creative Commons Attribution license (http://creativecommons.org/licenses/by/4.0/). 